\title{
Breast cancer in patients with $\mathrm{Li}-\mathrm{Fraumeni}$ syndrome - a case-series study and review of literature
}

\author{
Amara G Nandikolla \\ Sangeetha Venugopal \\ Jesus Anampa \\ Department of Oncology, Montefiore \\ Medical Center, Albert Einstein \\ College of Medicine, Albert Einstein \\ Cancer Center, Bronx, NY, USA
}

This article was published in the following Dove Press journal:

Breast Cancer - Targets and Therapy

23 March 2017

Number of times this article has been viewed

Background: Li-Fraumeni Syndrome (LFS) is a rare disease with autosomal dominant inheritance linked to germline mutations of tumor suppressor gene TP53. These patients are predisposed to malignancies such as sarcoma, breast cancer, leukemia, and other malignancies. Breast cancer, the most common malignancy in adult patients with LFS, has an early-onset presentation and is usually treated as per the guidelines for the general population due to the limited literature about breast cancer in LFS. We aimed to describe our institutional experience treating patients with breast cancer and LFS to contribute to literature about this entity.

Design: Retrospective single-institution case-series study. We searched for cases with LFS and breast cancer from 01/01/2000 to 12/31/2015 with treatment received at our institution.

Results: We identified 4 cases (2 African Americans, 1 Indian, and 1 Hispanic) in 4 different families, who were diagnosed with LFS after presenting with breast cancer. Three cases were triple-negative disease and 1 case was ER+, HER2 positive disease. They were treated with mastectomy and a third-generation breast chemotherapy regimen and/or trastuzumab-containing regimen. Radiation therapy was used in 2 patients. Breast cancer recurrence was seen in 1 patient, while three other malignancies were identified after breast cancer treatment ( 1 breast sarcoma, 1 leiomyosarcoma, and 1 myelodysplastic syndrome). A patient, who underwent surveillance with a positron emission tomography-computed tomography scan, was found to have a stage I leiomyosarcoma and was treated with surgical resection, but then developed metastatic disease requiring cytotoxic chemotherapy.

Conclusion: Breast cancer among patients with LFS needs a multidisciplinary treatment approach. Surgical management follows the guidelines for the general population. Risk-benefit assessment of chemotherapy and radiotherapy needs to be performed carefully in a case-bycase approach. Patients should undergo multimodality cancer surveillance, preferably in the context of a clinical trial.

Keywords: breast cancer, Li-Fraumeni syndrome, hereditary breast cancer, TP53

\section{Background}

Breast cancer is the most common female malignancy worldwide. Only $5 \%-10 \%$ of breast cancer cases are associated with hereditary syndromes, with BRCA1/2 mutations being the most commonly found. ${ }^{1} \mathrm{Li}$-Fraumeni syndrome (LFS) is a rare, highly penetrant, and autosomal dominant syndrome that occurs due to the germline mutation in the TP53 gene, ${ }^{2}$ which encodes the tumor suppressor protein p53. TP53 is involved in cell cycle regulation, apoptosis, and genomic stability; hence, TP53 has been named the "guardian of the genome". Missense mutations in the DNAbinding domain of the TP53 gene destroy the ability of the p53 protein to bind to its target DNA sequences, leading to not only loss of tumor suppressor function, but
Correspondence: Jesus Anampa Department of Oncology, Montefiore Medical Center, Albert Einstein College of Medicine, Albert Einstein Cancer Center, Bronx, NY 1046I, USA Email janampa@montefiore.org 
also gain of novel pro-oncogenic functions with different TP53 hotspot mutations exhibiting gain-of-function effects which may affect the age onset of certain cancers in LFS. ${ }^{3}$ As a consequence of abnormal cell cycle regulation, about $50 \%$ of TP53 mutation carriers develop cancer before age 30 years, with a cumulative lifetime risk up to $70 \%$ in men and $100 \%$ in women. ${ }^{4}$

The initial suggestion of this familial cancer syndrome was proposed by Frederick Li and Joseph Fraumeni when they reported 4 families that presented with soft-tissue sarcoma (STS), breast cancer, and other malignancies in children and young adults. ${ }^{5}$ It was not until 1988 when the original definition of LFS was presented from 24 families with autosomal dominant transmission of early-onset tumors including STSs, breast carcinomas, brain tumors, leukemias, and adrenocortical carcinomas before age 45 years. ${ }^{6}$ In 1990 , TP53 mutations were identified in 5 families with LFS, and TP53 germline mutation is considered the hallmark of LFS $;^{7}$ however, genetic TP53 modifiers have also been implicated in LFS. Wu et al reported that MDM2 polymorphism ( $\mathrm{T}>\mathrm{G}$ variant of SNP 309) was associated with accelerated tumor formation in both carriers and noncarriers of germline TP53 mutations. ${ }^{8}$ A recent study by Yao and Sherif revealed abrogation of DLL4 gene encoding a notch ligand, in LFS cells and tumor tissues and demonstrated that p53 binds to DLL4 promoter by association with CTCF. These findings suggest that DLL may play a role in cancer immune surveillance, and DLL4 dysregulation - such as in LFS - can contribute to widespread tumorigenesis. ${ }^{9}$

LFS criteria have changed since the first proposal of classic criteria in $1988 .{ }^{6}$ Birch et al $^{10}$ and Eeles ${ }^{11}$ defined the Li-Fraumeni-like (LFL) syndrome, to include patients who do not meet the classic LFS criteria, based on the occurrence of typical malignancies in both the proband and one or more relatives at a relatively early age. Moreover, Chompret criteria also included individuals at risk of carrying germline mutation in TP53 independently of family history (Table 1). ${ }^{12}$

LFS criteria are used in clinical practice to identify individuals with high risk who would benefit from TP53 mutation testing. TP53 germline mutations can be identified in $70 \%$ of families who meet the classic LFS criteria and $40 \%$ of those families meeting the LFL criteria; furthermore, the frequency of de novo mutations in TP53 is $\sim 7 \%-20 \% .{ }^{13}$ In addition, the combination of Chompret with classic criteria achieves the highest sensitivity (95\%) to identify patients with TP53 mutations. ${ }^{14}$

Early-onset breast cancer is one of the most common tumors in patients with LFS. ${ }^{15}$ Literature is scarce about the optimal management of patients with LFS and breast cancer, such as choosing the best adjuvant chemotherapy regimen due to concern of increasing risk of other malignancies. Moreover, adjuvant radiation for patients with LFS has been questioned due to concern of increased risk of radiationinduced sarcomas. Therefore, current management is based on a case-by-case approach. We aimed to describe our own experience in the management of breast cancer patients with LFS at our institution to contribute to the oncology literature on the management of this entity.

\section{Methods}

After obtaining institutional review board approval, we carried out a retrospective case-series study. Using our institutional "Clinical Looking Glass" software, we identified patients who had been diagnosed with breast cancer and LFS

Table I LFS and LFL syndrome criteria

\begin{tabular}{|c|c|}
\hline Classic LFS criteria & $\begin{array}{l}\text { - Proband diagnosed with sarcoma before age } 45 \text { and } \\
\text { - First-degree relative with a cancer diagnosis before age } 45 \text { and } \\
\text { - First- or second-degree relative with cancer diagnosis before age } 45 \text { or sarcoma at any age }\end{array}$ \\
\hline Chompret criteria for LFS & $\begin{array}{l}\text { - Proband diagnosed with a core LFS tumor (soft-tissue sarcoma, osteosarcoma, premenopausal breast } \\
\text { cancer, brain tumor, ACC, leukemia, or lung bronchoalveolar cancer) before age } 46 \text { years and at least } \\
\text { I first- or second-degree relative with a core LFS tumor (except breast cancer if the proband has breast } \\
\text { cancer) } \\
\text { - OR a proband with multiple primary tumors (except multiple breast cancers), } 2 \text { of which are LFS core } \\
\text { tumors, with the first occurring at age }<46 \text { years } \\
\text { - OR a proband with ACC or choroid plexus carcinoma, irrespective of family history }\end{array}$ \\
\hline Birch criteria for LFL syndrome & $\begin{array}{l}\text { - Proband with any childhood cancer, or sarcoma, brain tumor, or ACC diagnosed before age } 45 \text { and } \\
\text { - First- or second-degree relative with a core LFS cancer (sarcoma, breast cancer, brain tumor, ACC, or } \\
\text { leukemia) with onset at any age and } \\
\text { - First- or second-degree relative on the same side of the family with any cancer diagnosed before age } 60\end{array}$ \\
\hline Eeles criteria for LFL syndrome & $\begin{array}{l}\text { - Two first- or second-degree relatives with core LFS related malignancies (sarcoma, premenopausal breast } \\
\text { cancer, brain tumor, ACC, leukemia, or lung bronchoalveolar cancer) at any age }\end{array}$ \\
\hline
\end{tabular}

Abbreviations: ACC, adrenocortical carcinoma; LFL syndrome, Li-Fraumeni-like syndrome; LFS, Li-Fraumeni syndrome. 
from $01 / 01 / 2000$ to $12 / 31 / 2015$. We obtained baseline characteristics, pertinent history about breast cancer diagnosis, and management. Genetic counseling and testing records were also reviewed. Our study was approved by the Einstein East Campus Institutional Review Board. Patients provided informed consent to have their case details and imaging published as part of this study.

\section{Results}

During the study period, we identified 4 cases who met the inclusion criteria and who were treated at our institution. None of the patients were found to have BRCA $1 / 2$ or any other deleterious mutations associated with hereditary breast cancer (Table 2).

\section{Case I}

A 27-year-old African American (AA) female presented with self-palpable right breast mass. No significant past medical or family history was noted. Right breast ultrasound and magnetic resonance imaging (MRI) showed multiple masses (largest diameter $2.1 \mathrm{~cm}$ ). A positron emission tomographycomputed tomography (PET-CT) scan showed heterogeneous uptake in at least 4 foci in the right breast, axillary, subpectoral, and interpectoral lymph nodes. Core biopsy of the right breast revealed poorly differentiated invasive ductal carcinoma, ER+ (99\%), PR+ (85\%), and HER2 3+ by immunohistochemistry. She underwent genetic counseling with BreastNext analysis and she was found to be heterogeneous for the p.R248W (c.742C >t) pathogenic mutation in the TP53 gene, consistent with the diagnosis LFS. She received neoadjuvant chemotherapy with docetaxel, carboplatin, trastuzumab, and pertuzumab for 6 cycles, with good clinical response evidenced by posttreatment MRI. She underwent a right modified radical mastectomy plus sentinel lymph node biopsy (SLNB) and left prophylactic mastectomy. Surgical pathology specimen revealed ypT1bN0 breast cancer. She completed 52-week trastuzumab therapy; however, she did not receive adjuvant radiation. She is currently on ovarian function suppression plus anastrozole and she is undergoing annual surveillance with whole-body MRI without clinicoradiologic evidence of cancer recurrence. Her 4-year-old son was recently diagnosed with a left temporal high-grade neuroepithelial tumor, which required surgical resection; his genetic testing revealed the same deleterious TP53 mutation as mother.

\section{Case 2}

A 21-year-old Indian female presented with a $4 \mathrm{~cm}$ selfpalpable lump in the upper inner quadrant of the left breast.
No significant family history or past medical history was noted. She underwent diagnostic mammogram and MRI of the left breast, which revealed a $5.2 \mathrm{~cm}$ lesion at $2 \mathrm{~cm}$ from the nipple, and biopsy of the same showed ER/PR/HER2 negative poorly differentiated infiltrating ductal carcinoma with admixed lymphoid component. A PET-CT scan revealed hypermetabolic left breast with necrotic central necrosis and mild uptake in ipsilateral axillary lymph node. She was evaluated for inherited mutations and was found to be heterozygous for pathogenic mutation in p.T155N (c.464C>A) variant in TP53 gene, consistent with a diagnosis of LFS. She was started on neoadjuvant chemotherapy with weekly paclitaxel and showed clinically progressive disease after the second dose; therefore, treatment was switched to dosedense doxorubicin/cyclophosphamide for 6 cycles. She had excellent clinical response and underwent modified radical mastectomy with SLNB. She achieved complete pathologic response (ypT0N0) and received proton beam therapy to the left chest wall. She is currently disease-free and follows annual surveillance with breast MRI. Family members have not undergone genetic testing.

\section{Case 3}

A 16-year-old AA female presented with right shoulder osteosarcoma and received neoadjuvant therapy with methotrexate, doxorubicin, and cisplatin followed by surgical resection. At age 17 , she experienced sarcoma recurrence as a solitary lung mass and underwent surgical resection followed by therapy with IGF-1R antibody for a year in a clinical trial setting. She declined genetic counseling at that time. At age 19, she presented with a self-palpable right breast lump. Diagnostic mammogram revealed a $3.1 \mathrm{~cm}$ solid lesion in the upper inner quadrant of the right breast. PET-CT scan revealed a large hypermetabolic right breast mass with no metastases and small nonavid lymph nodes in the right axilla. Core biopsy of the right breast mass revealed ER/PR/HER2 negative poorly differentiated ductal carcinoma. Due to prior anthracycline treatment, she received neoadjuvant carboplatin/paclitaxel for 6 cycles with clinical progression; therefore, she underwent right mastectomy with SLNB (ypT3N0) and a prophylactic contralateral mastectomy (Figure 1). Given suspicion for LFS and its associated postradiation sarcoma risk, she did not receive adjuvant radiation, but was treated with adjuvant docetaxel/cyclophosphamide for 4 cycles. At age 20, she was found to have recurrent triple-negative breast cancer in the right axillary lymph nodes and lungs. The patient finally agreed to have genetic counseling, and BreastNext analysis found a heterozygous 5'UTR_3'UTR pathogenic mutation 
Table 2 Characteristics of patients with LFS and breast cancer $(n=4)$

\begin{tabular}{|c|c|c|c|c|c|c|c|}
\hline $\begin{array}{l}\text { Age } \\
\text { (years) }\end{array}$ & $\begin{array}{l}\text { Race/ } \\
\text { ethnicity }\end{array}$ & $\mathbf{F H}$ & Tumor grade & $\begin{array}{l}\text { Hormone } \\
\text { receptor }\end{array}$ & HER2/Neu & $\begin{array}{l}\text { Initial } \\
\text { stage }\end{array}$ & Surgery \\
\hline 27 & AA & Negative & $\begin{array}{l}\text { Moderate-poorly } \\
\text { differentiated }\end{array}$ & Positive & Amplified & $\mathrm{mT} 2 \mathrm{~N} 2 \mathrm{M} 0$ & $\begin{array}{l}\text { MRM + SLNB. Prophylactic } \\
\text { contralateral mastectomy }\end{array}$ \\
\hline 21 & South Asian & Negative & $\begin{array}{l}\text { Poorly } \\
\text { differentiated }\end{array}$ & Negative & Nonamplified & T3NIMO & $M R M+S L N B$ \\
\hline 19 & AA & $\begin{array}{l}\text { Breast cancer in } \\
\text { paternal aunt and } \\
\text { maternal great } \\
\text { grandmother }\end{array}$ & $\begin{array}{l}\text { Poorly } \\
\text { differentiated }\end{array}$ & Negative & Nonamplified & T3NOMO & $\begin{array}{l}\text { MRM + SLNB. Prophylactic } \\
\text { contralateral mastectomy }\end{array}$ \\
\hline 29 & Hispanic & Negative & $\begin{array}{l}\text { Poorly } \\
\text { differentiated }\end{array}$ & Negative & Nonamplified & T2NImi & Simple mastectomy + SLNB \\
\hline
\end{tabular}

Abbreviations: AA, African American; DdAC, dose-dense doxorubicin/cyclophosphamide; FH, family history; F/U, follow-up; LFS, Li-Fraumeni syndrome; MDS, myelodysplastic syndrome; MRM, modified radical mastectomy; NA, not applicable; OFS, ovarian function suppression; SLNB, sentinel lymph node biopsy; s/p, status post; $\mathrm{TAH}+\mathrm{BSO}$, total abdominal hysterectomy and bilateral salpingo-oophorectomy; TCH-P, docetaxel, carboplatin, trastuzumab, pertuzumab.

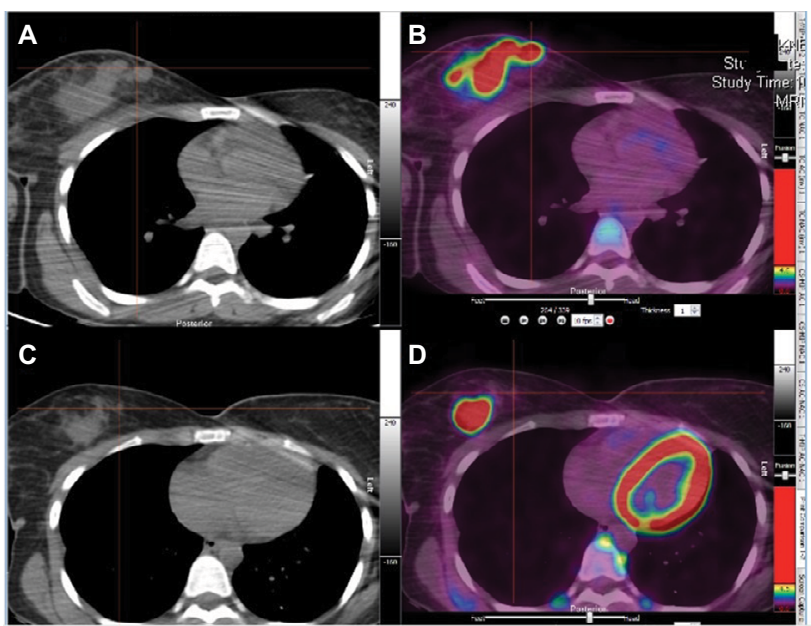

Figure I Pre-neoadjuvant chemotherapy PET-CT (C, D) and post-neoadjuvant chemotherapy PET-CT $(\mathbf{A}, \mathbf{B})$ in case 3 revealing right large mass with progression after neoadjuvant chemotherapy.

Abbreviation: PET-CT, positron emission tomography/computed tomography.

in the TP53 gene, consistent with the diagnosis of LFS. Multidisciplinary discussion recommended 5FU/doxorubicin/ cyclophosphamide and dexrazoxane for cardioprevention, given to her prior to anthracycline exposure during sarcoma treatment. After 2 cycles, she developed severe pancytopenia, for which she underwent a bone marrow biopsy and aspirate showed $8.9 \%$ CD34+ and/or CD117+myeloblasts, partial loss of CD10 expression on $36.3 \%$ mature granulocytes, and $\sim 25 \%$ erythroid precursor cells expressing CD71 and CD235. Cytogenetics revealed $5 \mathrm{q}$ deletion and monosomy 7 , diagnosis consistent with myelodysplastic syndrome (MDSRAEB). She was started on azacitidine. Unfortunately, she had progression with her lung metastases and succumbed to the disease 10 months after breast cancer recurrence. The patient had a paternal aunt with breast cancer diagnosed at age 50 years (unknown treatment) and maternal great grandmother with breast cancer diagnosed at an unknown age; however, her family members have not undergone genetic counseling.

\section{Case 4}

A 28-year-old Hispanic female presented with left breast malignant phyllodes tumor and was treated with surgical resection. At age 29 she noticed a right breast mass with right breast diagnostic mammogram and MRI revealing a $1.7 \mathrm{~cm}$ mass at the upper outer quadrant and prominent right axillary nodes. Breast mass core biopsy showed invasive mammary carcinoma, high nuclear grade with lymphoplasmacytic infiltrate, ER/PR/HER2 negative. She was referred for genetic counseling and was found to have a p.H193R TP53 pathogenic mutation compatible with LFS. She underwent right simple mastectomy with SLNB revealing a pT2N1mi ductal carcinoma. She then received adjuvant dose-dense doxorubicin/cyclophosphamide for 4 cycles and weekly paclitaxel for 12 cycles, followed by adjuvant radiotherapy to the chest wall. At age 33, a follow-up mammogram revealed a new left upper outer quadrant mass. Breast mass biopsy was consistent with highly cellular spindle cell neoplasm with moderate atypia. She underwent left mastectomy with SLNB and the surgical specimen was consistent with spindle cell sarcoma arising from the patient's prior phyllodes tumor. At age 36, annual surveillance with PET-CT revealed avid uptake in the uterus (Figure 2). Given the diagnosis of LFS 


\begin{tabular}{|c|c|c|c|c|c|c|}
\hline Chemotherapy & Radiotherapy & $\begin{array}{l}\text { Endocrine } \\
\text { therapy }\end{array}$ & $\begin{array}{l}\text { TP53 } \\
\text { mutation }\end{array}$ & Other cancers & $\begin{array}{l}\text { F/U } \\
\text { (months) }\end{array}$ & Outcome \\
\hline $\begin{array}{l}\text { Neoadjuvant TCH-P } \times \\
6 \text { cycles. Finished total } \\
52 \text {-week trastuzumab }\end{array}$ & None & $\begin{array}{l}\text { OFS and } \\
\text { anastrozole }\end{array}$ & $\begin{array}{l}\text { p.R248W } \\
\text { (c.742C>t) }\end{array}$ & None & 18 & $\begin{array}{l}\text { Alive without } \\
\text { recurrence }\end{array}$ \\
\hline $\begin{array}{l}\text { Neoadjuvant paclitaxel } \times 2 \\
+ \text { DdAC } \times 6\end{array}$ & $\begin{array}{l}\text { Proton beam } \\
\text { therapy }\end{array}$ & NA & $\begin{array}{l}\text { p.TI55N } \\
(\text { c. } 464 \mathrm{C}>\mathrm{A})\end{array}$ & None & 35 & $\begin{array}{l}\text { Alive without } \\
\text { recurrence }\end{array}$ \\
\hline $\begin{array}{l}\text { Neoadjuvant carboplatin/ } \\
\text { paclitaxel } \times 6 \text { cycles. } \\
\text { Adjuvant docetaxel/ } \\
\text { cyclophosphamide } \times 4\end{array}$ & None & NA & $\begin{array}{l}\text { 5'UTR_3'UTR } \\
\text { del }\end{array}$ & Osteosarcoma & 35 & $\begin{array}{l}\text { Breast cancer } \\
\text { recurrence after } \\
\text { I } 3 \text { months, developed } \\
\text { MDS and died }\end{array}$ \\
\hline $\begin{array}{l}\text { Adjuvant DdAC } \times 4+ \\
\text { paclitaxel } \times 12\end{array}$ & Yes & NA & $\begin{array}{l}\text { p.HI93R } \\
\text { (c.578A>G) }\end{array}$ & $\begin{array}{l}\text { Malignant phyllodes tumor. } \\
\text { Uterine leiomyosarcoma } \\
\text { s/p TAH + BSO, developed } \\
\text { lung metastasis treated with } \\
\text { docetaxel/gemcitabine for } \\
8 \text { cycles with stable disease }\end{array}$ & 110 & $\begin{array}{l}\text { Alive. Contralateral } \\
\text { breast sarcoma s/p } \\
\text { mastectomy }\end{array}$ \\
\hline
\end{tabular}

Figure 2 Surveillance PET-CT revealing uterine uptake, which led to diagnosis of stage I uterine leiomyosarcoma.

Abbreviation: PET-CT, positron emission tomography-computed tomography.

and concern for malignancy, she underwent total abdominal hysterectomy plus bilateral oophorectomy which revealed a 5 $\mathrm{cm}$ high-grade leiomyosarcoma (pT1aNx). Eighteen months later, a surveillance computed tomography $(\mathrm{CT})$ of the chest showed multiple subcentimeter nodules in both lungs; a biopsy revealed metastatic leiomyosarcoma and she was started on gemcitabine/docetaxel for 8 cycles. Most recent imaging revealed stable disease. Of note, her daughter was recently diagnosed with rhabdomyosarcoma at age 3 years.

\section{Discussion and review of literature Epidemiology of breast cancer in LFS}

In adults, breast cancer is the most common cancer among female patients with LFS, which is present in up to $79 \%$ of affected TP53 mutation carriers, followed by STS $(27 \%$ of mutation carriers). A study revealed that none of the 59 male patients with TP53 mutations were found to have breast cancer, suggesting a correlation of breast cancer risk only for females. Most patients are found to have HER2amplified (55\%) or ER+/PR+/HER2+ (37\%) tumors, ${ }^{16}$ and contralateral disease is present in $\sim 31 \%$ patients with LFS. The annual hazard rate of breast cancer in LFS increases significantly after the second decade and peaks around age 40. A recent study revealed that the cumulative incidence of breast cancer is $\sim 85 \%$ by age 60 , which is comparable to the cumulative incidence for BRCA $1 / 2$ mutation carriers. ${ }^{13}$ In our study, all our patients presented with early-onset breast cancer (before age 30 years), 3 patients had triple-negative disease, and 1 patient had ER+, PR+, HER2+ disease, and all of them revealed poorly differentiated features. These differences compared to other studies could be explained by our small sample size and diverse ethnical/racial population (2 AA, 1 Indian, and 1 Hispanic).

\section{Breast cancer screening and work-up}

National Comprehensive Cancer Network (USA) guidelines for breast cancer screening in LFS recommend clinical breast exam and breast screening with annual MRI \pm mammogram until age 75 and consideration of risk-reducing mastectomy. ${ }^{17}$ The work-up for patients with LFS should follow standard 
guidelines. Emphasis should be made that teenagers may benefit from sonogram and/or breast MRI due to dense breast tissue, while young adults would require mammogram and/or breast MRI. In our study, none of the patients was diagnosed by screening mammogram/MRI, since they were diagnosed with LFS after breast cancer presentation. Most patients required breast MRI and PET-CT due to dense tissue and/or locally advanced disease.

\section{Surgical considerations in breast cancer and LFS}

Several studies have demonstrated similar mortality rates when comparing total mastectomy to breast conserving surgery followed by radiotherapy in the management of early breast cancer. ${ }^{18}$ Surgical local treatment in patients with LFS should follow the same guidelines as in the general population based on the clinicopathologic features of breast cancer and other medical comorbidities. However, in the absence of major contraindications, total mastectomy could be preferred over breast conserving surgery in order to avoid the need of adjuvant radiation, as radiation may predispose to secondary malignancies in patients with LFS. Axillary staging and management should follow standard guidelines. Due to the high risk for breast cancer in patients with LFS, discussion of risks and benefits of prophylactic mastectomy needs to be addressed in all cases. All of our patients were treated with mastectomy and 2 underwent prophylactic contralateral mastectomy. In our cohort, case 4 developed new contralateral breast sarcoma in the setting of a prior malignant phyllodes tumor and case 3 developed breast cancer recurrence in ipsilateral axillary lymph nodes despite bilateral mastectomies.

\section{Adjuvant chemotherapy for breast cancer in LFS}

Adjuvant chemotherapy with third-generation regimens, anthracycline-taxane based, has shown to reduce local and distant recurrence and decrease mortality by $\sim 30 \%$ in patients with early breast cancer. ${ }^{19}$ Since TP53 is an important gene in the DNA damage response pathway, patients with LFS may be more susceptible to the carcinogenic effect of DNAdamaging drugs and ionizing radiation. ${ }^{1}$ Moreover, literature suggests that patients with germline TP53 mutations have limited response to pre- or postoperative chemotherapy. ${ }^{20,21}$ Alkylating agents and anthracyclines induce p53-dependent apoptosis; therefore, their effect in patients with TP53 mutations might not be optimal, leading to treatment resistance. ${ }^{22}$ Microtubule stabilizers, such as paclitaxel, act by inhibiting microspindle formation, independent of p53 involvement.
Loss of cell cycle arrest due to p53 deficiency may allow cells to undergo $\mathrm{S}$ phase with more effective mitosis, thus making paclitaxel a potential better chemotherapy option for these patients. ${ }^{22}$ In our study, case 2 developed rapid clinical progression after 2 cycles of paclitaxel, but achieved good clinical response after switching to doxorubicin/cyclophosphamide. Case 3 had clinical progression during neoadjuvant carboplatin/paclitaxel and also had recurrence despite adjuvant docetaxel/cyclophosphamide; she also developed MDS that may have developed due to prior anthracycline use. Her MDS was very aggressive, of high risk, and was poorly responsive to azacitidine. Chemotherapy regimen should be selected based on a case-by-case approach. We recommend that these patients should be treated with the regimen that offers the best improvement in breast cancer survival, such as anthracycline-taxane-based regimens, since the patients are at increased risk for carcinogenesis leading to breast cancer recurrence; also, they should be followed closely for the potential development of secondary malignancies associated with chemotherapy.

\section{Adjuvant radiation for breast cancer in LFS}

Radiotherapy is an important adjuvant therapy for early breast cancer, which reduces the 10-year recurrence rate (absolute reduction $15.7 \%$ ) and the 15 -year mortality rate (absolute reduction 3.8\%). ${ }^{23}$ Radiation-induced malignancies are rare, with an incidence $\sim 2 \%$ and a latency period of $10-15$ years after radiation treatment. ${ }^{24,25}$ Patients with LFS treated with radiation have increased risk of developing sarcomas or leukemias and a shorter latent period. ${ }^{26}$ Limacher et al, in an anecdotal report, observed the development of metachronous cancers in the irradiated field of breast cancers in a patient with LFS. ${ }^{27}$ Heymann et al reported that among 6 patients with LFS who received adjuvant radiotherapy, 11 events occurred (3 ipsilateral breast recurrences, 3 contralateral breast cancers, 2 radiation-induced cancers, and 3 new primaries). ${ }^{24}$ p53-deficient cells are unable to arrest cell cycle or undergo apoptosis following radiation; moreover, these cells have increased resistance to DNA-damaging agents such as radiation. ${ }^{28}$ Mice studies have shown that $\mathrm{p} 53$ plays a major role in tumor suppression by preserving genomic integrity through G1 arrest or apoptosis in response to radiationinduced damage to cells. A few mice models have reiterated that low-dose radiation in p53-deficient mice decreases the tumor latency with development of early-onset sarcomas and lymphomas. ${ }^{29}$ Several case reports in LFS patients treated with radiation have shown rapid sarcoma development. ${ }^{30,31}$ 
In our cohort, in order to avoid surrounding tissue damage, case 2 received proton beam radiation and she remains disease-free; case 4 received ionizing radiation and developed contralateral breast sarcoma, and subsequent follow-up revealed metastatic uterine leiomyosarcoma. Given the risk of treatment-related complications, radiation as adjuvant therapy should be given careful consideration in LFS patients and offered in a case-by-case fashion.

\section{Cancer surveillance in LFS}

Patients with LFS and LFL syndrome are predisposed to a variety of cancers in their lifetime. Surveillance would be beneficial to detect early malignancies in asymptomatic patients. Masciari et al tested the use of F18-fluorodeoxyglucose-PET/ $\mathrm{CT}$ as a potential screening tool. Among 15 asymptomatic LFS patients, they detected 2 papillary thyroid carcinomas and 1 esophageal carcinoma; all of the cancers were early stage and treated with curative intent. ${ }^{32}$ However, the amount of radiation exposure in LFS patients using this screening strategy was concerning. The National Institutes of Health LFS study enrolled 100 patients who underwent blood tests, abdominal ultrasound, annual brain MRI, annual rapid whole-body MRI, annual breast $\mathrm{MRI} / \mathrm{mammogram}$, and colonoscopy every 3 years and identified 6 cancers (all identified by MRI), leading to a cancer detection rate of $6 \%$ and false-positive rate of $79 \% .{ }^{33}$ The multimodal Toronto protocol evaluated surveillance for adrenocortical carcinoma (abdominal ultrasound and blood/urine biomarkers), breast cancer (annual mammogram and MRI, breast selfexam, clinical breast exam), brain tumor (annual brain MRI), soft-tissue and bone sarcoma (annual rapid whole-body MRI, abdominal ultrasound), leukemia/lymphoma(complete blood count, erythrocyte sedimentation rate, lactate dehydrogenase), colorectal cancer (colonoscopy every 2 years), and melanoma (annual dermatologic exam) along with a general assessment (physical exam every 3-4 months). Among 39 families, 40 patients underwent surveillance and 49 declined surveillance (however, 19 patients then crossed to the surveillance group). With $90 \%-100 \%$ compliance rate to surveillance protocol, they identified 40 asymptomatic neoplasms in 19 of 59 patients who underwent surveillance and 61 symptomatic neoplasms among 43 of 49 patients in the nonsurveillance group. Eightyfour percent of individuals in the surveillance group were alive at 38 months, while only $49 \%$ in the nonsurveillance group were alive at 46 months. The 5 -year overall survival rates were $88.8 \%$ and $59.6 \%$ for the surveillance and nonsurveillance groups, respectively. ${ }^{34}$ Other studies are currently evaluating different screening strategies, ${ }^{15}$ such as the LIFESCREEN French project (NCT01464086), the SIGNIFY trial in the
UK (NCT01737255), US NIH (NCT01443468), Dana-Farber Cancer Institute study (NCT02950987), and the Australian surveillance study in multiorgan cancer prone syndromes (ACTRN12613000987763).

In our study, PET-CT surveillance for case 4 identified a stage I uterine leiomyosarcoma, which was treated with surgery but the patient developed metastatic disease later in the course. Case 1 recently started annual whole-body MRI surveillance without identification of any malignancy. Currently published recommendations for LFS cancer screening include National Comprehensive Cancer Network guidelines, National Institute for Health and Care Excellence guidelines, and eviQ cancer treatments online (Table 3). Available data suggest that an intensive screening strategy should be offered to patients with LFS. MRI-based screening seems to be an attractive option, given the absence of radiation exposure. Since no randomized trial has been reported, along with the psychologic stress of false-positive findings requiring invasive procedures, we suggest that cancer screening should be preferably performed in a clinical trial context.

\section{Conclusion}

We report a cohort of 4 patients in different families, representing a heterogeneous racial/ethnical background, without significant prior family history suggesting TP53 mutations. Triple-negative disease was the most common histology, and all patients were treated with third-generation breast chemotherapy regimens and/or trastuzumab-containing regimens. Three patients are alive without breast cancer recurrence. Proton beam radiation was well tolerated in 1 patient, which was administered to limit exposure of radiation to the surrounding tissue. Risk-benefit assessment of chemotherapy and radiotherapy needs careful consideration due to the risk of treatment resistance and associated secondary malignancies. Cancer screening should be discussed in patients with LFS, and multimodality strategy in the context of a clinical trial should be preferred.

\section{Acknowledgments}

The research described was supported by NIH/National Center for Advancing Translational Science (NCATS) Einstein-Montefiore CTSA Grant Number UL1TR001073 and the Einstein Paul Calabresi Career Development Program (NIH 5K12CA132783-08)

\section{Author contributions}

AGN helped in acquisition of relevant literature, data acquisition, drafting the manuscript, revising critical and intellectual 
Table 3 Cancer screening recommendations for patients with LFS

\begin{tabular}{|c|c|c|c|}
\hline & NCCN & NICE & eviQ \\
\hline & USA & UK & Australia \\
\hline Breast & $\begin{array}{l}\text { - Clinical exam every 6-12 months, } \\
\text { starting at age } 20-25 \text { years } \\
\text { - Age } 20-29 \text { years, annual MRI with } \\
\text { contrast or mammogram if MRI } \\
\text { unavailable } \\
\text { - Age } 30-75 \text { years, annual mammogram } \\
\text { and breast MRI with contrast } \\
\text { - Age }>75 \text { years, management on } \\
\text { individual basis } \\
\text { - Discuss risk-reducing mastectomy }\end{array}$ & $\begin{array}{l}\text { - } 20-49 \text { years, annual breast MRI } \\
\text { - 50-70 years, consider annual } \\
\text { breast MRI }\end{array}$ & $\begin{array}{l}\text { - 20-50 years, annual breast MRI. } \\
\text { Mammogram/ultrasound should be } \\
\text { considered only if unable to access MRI }\end{array}$ \\
\hline Colon & $\begin{array}{l}\text { - Colonoscopy every } 2-5 \text { years starting at } \\
\text { age } 25 \text { years or } 5 \text { years before earliest } \\
\text { colon cancer in the family }\end{array}$ & & $\begin{array}{l}\text { - Colonoscopy every } 2-5 \text { years from age } \\
25 \text { years or younger if there is a family } \\
\text { history of bowel cancer }\end{array}$ \\
\hline $\begin{array}{l}\text { Other } \\
\text { cancers }\end{array}$ & $\begin{array}{l}\text { - Address limitations of screening for } \\
\text { many cancers associated with LFS } \\
\text { - Annual comprehensive H\&P (including } \\
\text { neurologic examination) } \\
\text { - Annual dermatologic examination } \\
\text { - Annual whole-body MRI (or equivalent), } \\
\text { preferably in the context of a clinical trial } \\
\text { - Brain MRI }\end{array}$ & & $\begin{array}{l}\text { - Annual H\&P } \\
\text { - Further investigations if clinically } \\
\text { indicated }\end{array}$ \\
\hline
\end{tabular}

Abbreviations: eviQ, eviQ cancer treatments online; H\&P, history and physical exam; LFS, Li-Fraumeni syndrome; MRI, magnetic resonance imaging; NCCN, National Comprehensive Cancer Network; NICE, National Institute for Health and Care Excellence.

content, tables creation, tables editing, figure creation and editing and final approval of the version to be published. SV contributed to acquisition of relevant literature, data acquisition, drafting the manuscript, final approval of the version to be published. JA carried out conception and design of the work, acquisition of relevant literature, data acquisition, manuscript writing, manuscript editing, revising critical and intellectual content, tables creation, tables editing, figure creation and editing, and final approval of the version to be published.

\section{Disclosure}

The authors report no conflicts of interest in this work.

\section{References}

1. de Bruin MA, Ford JM, Kurian AW. A young woman with bilateral breast cancer: identifying a genetic cause and implications for management. J Natl Compr Canc Netw. 2013;11(5):512-517.

2. Damineni S, Rao VR, Kumar S, et al. Germline mutations of TP53 gene in breast cancer. Tumour Biol. 2014;35(9):9219-9227.

3. Xu J, Qian J, Hu Y, et al. Heterogeneity of Li-Fraumeni syndrome links to unequal gain-of-function effects of p53 mutations. Sci Rep. 2014;4:4223.

4. Chompret A, Brugieres L, Ronsin M, et al. P53 germline mutations in childhood cancers and cancer risk for carrier individuals. Br J Cancer. 2000;82(12):1932-1937.

5. Li FP, Fraumeni JF Jr. Rhabdomyosarcoma in children: epidemiologic study and identification of a familial cancer syndrome. J Natl Cancer Inst. 1969;43(6):1365-1373.

6. Li FP, Fraumeni JF Jr, Mulvihill JJ, et al. A cancer family syndrome in twenty-four kindreds. Cancer Res. 1988;48(18):5358-5362.
7. Malkin D, Li FP, Strong LC, et al. Germ line p53 mutations in a familial syndrome of breast cancer, sarcomas, and other neoplasms. Science. 1990;250(4985):1233-1238.

8. Wu CC, Krahe R, Lozano G, et al. Joint effects of germ-line TP53 mutation, MDM2 SNP309, and gender on cancer risk in family studies of Li-Fraumeni syndrome. Hum Genet. 2011;129(6):663-673.

9. Yao Z, Sherif ZA. The effect of epigenetic silencing and TP53 mutation on the expression of DLL4 in human cancer stem disorder. Oncotarget. 2016;7(39):62976-62988.

10. Birch JM, Hartley AL, Tricker KJ, et al. Prevalence and diversity of constitutional mutations in the p53 gene among $21 \mathrm{Li}$-Fraumeni families. Cancer Res. 1994;54(5):1298-1304.

11. Eeles RA. Germline mutations in the TP53 gene. Cancer Surv. 1995; 25:101-124.

12. Tinat J, Bougeard G, Baert-Desurmont S, et al. 2009 version of the Chompret criteria for Li Fraumeni syndrome. J Clin Oncol. 2009;27(26): e108-e109.

13. Mai PL, Best AF, Peters JA, et al. Risks of first and subsequent cancers among TP53 mutation carriers in the National Cancer Institute LiFraumeni syndrome cohort. Cancer. 2016;122(23):3673-3681.

14. Gonzalez KD, Noltner KA, Buzin CH, et al. Beyond Li Fraumeni Syndrome: clinical characteristics of families with p53 germline mutations. J Clin Oncol. 2009;27(8):1250-1256.

15. McBride KA, Ballinger ML, Killick E, et al. Li-Fraumeni syndrome: cancer risk assessment and clinical management. Nat Rev Clin Oncol. 2014;11(5):260-271.

16. Bougeard G, Renaux-Petel M, Flaman JM, et al. Revisiting LiFraumeni syndrome from TP53 mutation carriers. J Clin Oncol. 2015; 33(21):2345-2352.

17. NCCN guidelines (version 2.2017); 2017. Available from: https:// www.nccn.org/professionals/physician_gls/pdf/genetics_screening. pdf. Accessed March 2, 2017.

18. Jatoi I, Proschan MA. Randomized trials of breast-conserving therapy versus mastectomy for primary breast cancer: a pooled analysis of updated results. Am J Clin Oncol. 2005;28(3):289-294. 
19. Anampa J, Makower D, Sparano JA. Progress in adjuvant chemotherapy for breast cancer: an overview. BMC Med. 2015;13:195.

20. Kappel S, Janschek E, Wolf B, et al. TP53 germline mutation may affect response to anticancer treatments: analysis of an intensively treated Li-Fraumeni family. Breast Cancer Res Treat. 2015;151(3):671-678.

21. Lowe SW, Ruley HE, Jacks T, Housman DE. p53-dependent apoptosis modulates the cytotoxicity of anticancer agents. Cell. 1993; 74(6):957-967.

22. Kandioler-Eckersberger D, Ludwig C, Rudas M, et al. TP53 mutation and $\mathrm{p} 53$ overexpression for prediction of response to neoadjuvant treatment in breast cancer patients. Clin Cancer Res. 2000;6(1):50-56.

23. Darby S, McGale P, Correa C, et al. Effect of radiotherapy after breast-conserving surgery on 10 -year recurrence and 15 -year breast cancer death: meta-analysis of individual patient data for 10,801 women in 17 randomised trials. Lancet (London, England). 2011; 378(9804):1707-1716.

24. Heymann S, Delaloge S, Rahal A, et al. Radio-induced malignancies after breast cancer postoperative radiotherapy in patients with LiFraumeni syndrome. Radiat Oncol. 2010;5:104.

25. Rubino C, de Vathaire F, Shamsaldin A, Labbe M, Le MG. Radiation dose, chemotherapy, hormonal treatment and risk of second cancer after breast cancer treatment. Br J Cancer. 2003;89(5):840-846.

26. Hisada M, Garber JE, Fung CY, Fraumeni JF, Jr., Li FP. Multiple primary cancers in families with Li-Fraumeni syndrome. J Natl Cancer Inst. 1998;90(8):606-611.
27. Limacher JM, Frebourg T, Natarajan-Ame S, Bergerat JP. Two metachronous tumors in the radiotherapy fields of a patient with Li-Fraumeni syndrome. Int J Cancer. 2001;96(4):238-242.

28. Lee JM, Abrahamson JL, Kandel R, Donehower LA, Bernstein A. Susceptibility to radiation-carcinogenesis and accumulation of chromosomal breakage in p53 deficient mice. Oncogene. 1994;9(12):3731-3736.

29. Kemp CJ, Wheldon T, Balmain A. p53-deficient mice are extremely susceptible to radiation-induced tumorigenesis. Nat Genet. 1994; 8(1):66-69.

30. Chadaz T, Hobbs SK, Son H. Chest wall sarcoma: 18F-FDG PET/ CT in a patient with Li-Fraumeni syndrome. Clin Nucl Med. 2013; 38(10):818-820.

31. Salmon A, Amikam D, Sodha N, et al. Rapid development of postradiotherapy sarcoma and breast cancer in a patient with a novel germline 'de-novo' TP53 mutation. Clin Oncol (R Coll Radiol). 2007; 19(7):490-493.

32. Masciari S, Van den Abbeele AD, Diller LR, et al. F18-fluorodeoxyglucose-positron emission tomography/computed tomography screening in Li-Fraumeni syndrome. JAMA. 2008;299(11):1315-1319.

33. Mai PL. Baseline cancer screening findings from the NCI Li-Fraumeni syndrome study; 2016. ASCO Annual meeting; 2016. Chicago, IL, USA

34. Villani A, Shore A, Wasserman JD, et al. Biochemical and imaging surveillance in germline TP53 mutation carriers with Li-Fraumeni syndrome: 11 year follow-up of a prospective observational study. Lancet Oncol. 2016;17(9):1295-1305.
Breast Cancer - Targets and Therapy

\section{Publish your work in this journal}

Breast Cancer - Targets and Therapy is an international, peerreviewed open access journal focusing on breast cancer research, identification of therapeutic targets and the optimal use of preventative and integrated treatment interventions to achieve improved outcomes, enhanced survival and quality of life for the cancer patient

\section{Dovepress}

The manuscript management system is completely online and includes a very quick and fair peer-review system, which is all easy to use. Visit http://www.dovepress.com/testimonials.php to read real quotes from published authors. 